\title{
Alzheimer's disease and type 2 diabetes mellitus: Risk factors and effectiveness of antidiabetic agents in treatment of Alzheimer's disease
}

\author{
Aye Aye Myint ${ }^{1, *}$, Kyaw Soe Win ${ }^{2}$, Zaw Aung $^{3}$ \\ ${ }^{1}$ Jeffrey Cheah School of Medicine and Health Sciences, Monash University Sunway Campus, Clinical School Johor Bahru, Johor Bahru, \\ Malaysia \\ ${ }^{2}$ Lashio General Hospital, Myanmar \\ ${ }^{3}$ Faculty of Medicine and Health Sciences, UCSI University, Terengganu Campus, Terengganu, Malaysia
}

Email address:

a2myintster@gmail.com(Myint A. A.), kyawsoewin2006@gmail.com(Win K. S.), za.january@gmail.com(Aung Z.)

\section{To cite this article:}

Aye Aye Myint, Kyaw Soe Win, Zaw Aung. Alzheimer's Disease and Type 2 Diabetes Mellitus: Risk Factors and Effectiveness of Antidiabetic Agents in Treatment of Alzheimer's Disease. Science Journal of Clinical Medicine. Vol. 2, No. 3, 2013, pp. 114-121. doi: $10.11648 /$ j.sjcm. 20130203.20

\begin{abstract}
The aim of this review is to highlight the association between type 2 diabetes mellitus (DM) and cognitive impairment/Alzheimer's disease (AD) and provide an updated summary of the evidence related to various potentially modifiable risk factors such as hyperinsulinaemia,insulin resistance,hypo-and hyperglycaemia, vascular risk factors like hypertension and obesity, micro and macrovascular complications, depression in AD.Treating modifiable risk factors can reduce the prevalence of AD.In addition we provide the information about potential benefits of antidiabetic agents for slowing of cognitive decline and $\mathrm{AD}$ in patients with type2 $\mathrm{DM}$. There were studies demonstrating the novel effects of antidiabetic agents on neuronal functions by increased insulin signaling in an AD brain with a neuroprotective and neurotrophic effect. In this regard insulin, metformin and thiazolidinediones (in particular, rosiglitazone and pioglitazone ) would have potential protective effect for the development of AD.
\end{abstract}

Keywords: Alzheimer's Disease, Anti-Diabetic Medication, Dementia, Type 2 Diabetes

\section{Introduction}

Alzheimer's disease is one of the most common types of dementia, comprising about $60-80 \%$ of the dementia cases. Dementia is one of the most frequent neurodegenerative disorders in the elderly due to the increasing life expectancy. According to the estimates the number of dementia patients will be raised from 24.3 million in 2001 to 81.1 million in 2040 worldwide [1,2].

Both longitudinal and cross-sectional studies have shown compelling evidence that type 2 diabetes mellitus (type 2DM) has an increased risk of cognitive impairment and dementia [3-9]. In general, the incidence of dementia in diabetes is raised by $50 \%-100 \%$ compared to people without diabetes. Therefore presently 1 in $10-15$ cases of dementia are attributable to diabetes $[10,11]$.

Population based studies identified that type 2 diabetes is one of the modifiable risk factors for Alzheimer's disease (AD) and has a 1.5 to 2 fold increased risk to develop cognitive impairment [10-17]. Among the various types of predictors the macrovascular disease is a strong predictor of dementia in diabetes. The observational studies have identified an association between type $2 \mathrm{DM}$ and increased risk of cognitive impairment and dementia, Alzheimer's disease.The common pathological finding in both conditions is the deposition of significant quantities of amyloid in the brain and pancreas. They are characterized by fibrillar protein aggregates - amylin in diabetic's pancreatic islets, and $\beta$-Amyloid (A $\beta)$ and neurofibrillary tangles (NFTs) in AD brain. Amylin accumulation leads to pancreatic $\beta$-cell loss in cases of diabetes, and A $\beta$ and NFT formation cause neuronal cell loss in cases of dementia. Therefore type $2 \mathrm{DM}$ and $\mathrm{AD}$ is considered as a disease with similar pathological process.

There are two forms of Alzheimer's disease; familial and sporadic forms. The autosomal dominant type, familial forms usually manifest before age 65 , and $5 \%$ of cases develop AD in the fifth decade or earlier [18].

In sporadic forms, the prevalence has been found to 
correlate with various environmental factors related to oxidative stress and aetiology is multifactorial .Age is being a key risk factor in which some genetic polymorphisms are known to be as predisposing factors [19].

\section{Risk Factors for AD in Type 2 DM}

Management of potentially modifiable risk factors may reduce cognitive decline in cases of type 2 diabetes with AD.AD prevention strategies would have the greatest effect on $\mathrm{AD}$ prevalence.

\section{Hyperinsulinaemia and Insulin Resistance}

Insulin secretion and action are two important components of glucose metabolism and the development of glucose intolerance in type 2 DM [20]. In general insulin acts as a major role in memory and brain function in patients with AD. On Brain, CNS insulin influences cognitive function by regulating neuronal functions, neurogenesis and neurotransmitter regulation. Insulin also controls levels of the beta amyloid peptide in the brain. In neuropathological studies of patients with AD showed that reduced insulin signaling may alter the normal function of brain insulin. [21-23].

Plasma insulin concentration is elevated in patients with type 2 DM because of peripheral insulin resistance. Hyperinsulinaemia is one of the predictors of memory impairment and AD [24]. Large population's studies on vascular risk factors have demonstrated that an increase in brain insulin is found to be associated with poor performances on the MMSE. Epidemiological studies of non-diabetic adults showed that high concentration of insulin in the brain was associated with poor memory performance and an increased risk of $\mathrm{AD}$ [26-30]. AD patients with lower concentrations of insulin in the cerebrospinal fluid may develop neuronal dysfunction [31, 32]. But the mechanism of cognitive impairment of insulin resistance and hyperinsulinaemia remains speculative [25].

\section{Hyperglycemia}

It has been postulated that chronic hyperglycemia is associated with increased speed of cognitive impairment in the elderly. Studies in human and animal models showed that even the moderate increases in glucose levels can affect cognitive function [31].

Studies in patients with type 1 diabetes suggested that chronic hyperglycemia may cause memory impairment. Cross-sectional studies in patients with type 2 diabetes also observed similar finding. The DCCT study demonstrated that cognitive function was deteriorated by cerebral micro vascular disease, induced by chronic hyperglycemia [32] . One study highlighted that oxidative stress of hyperglycemia can have a direct neurotoxic effect on brain cells [33].

Data from the Kungsholmen project showed that very old patients with uncontrolled diabetes $(\mathrm{Hb}$ $\mathrm{A} 1 \mathrm{C}>11 \mathrm{mmol} / \mathrm{L}$ ) had the highest risk of $\mathrm{AD}$ and stroke independent of vascular co-morbidities [34].

\section{Hypoglycemia}

Hypoglycemia especially is a well-known complication of type 1 diabetes than type 2 DM. In hypoglycemic, if the blood glucose level is low below $3.0 \mathrm{mmol} / \mathrm{L}$, brain cognitive function is rapidly deteriorating and it regains with normal glucose levels [35, 36]. The studies have observed that the frequency of severe hypoglycemia was not associated with poor cognitive function over the 18 year study period [32].

The Fremantle diabetes study has found that there were no significant findings of cognitive impairment by severe hypoglycemia in the older type 2 diabetic patients [37]. So far there are no data to identify the adverse effects of hypoglycemia on cognitive function in type 2 diabetic patients.

\section{Vascular Risk Factors}

One of the contributing factors for $\mathrm{AD}$ pathology is poor cerebral perfusion which may be accelerated by preexisting cerebral micro vascular abnormalities [38].

In the general population, the risk of dementia is increased with vascular risk factors such as hypertension, dyslipidaemia and obesity especially present at middle age [39]. In the elderly, the association between cardiovascular risk factors and cognitive impairment is generally less consistent [40, 41].

Diabetes is usually accompanied by common cardiovascular risk factors, such as hypertension, dyslipidaemia and obesity, which might harm the brain function. There is evidence that dyslipidaemia was one of the causes for poor memory function in middle-aged patients with diabetes [42]. One longitudinal study in elderly patients with diabetes observed that cognitive decline has found to be associated with higher baseline total cholesterol [43].

In addition, a cross- sectional study showed better cognitive function with the use of lipid-lowering drugs. [44]. One longitudinal study reported that poor cognitive performance in type 2 diabetic patients was related to long term exposure to hypertension [45].

Obesity is not only an important risk factor for the development of type 2 diabetes mellitus but also modifiable risk factors for $\mathrm{AD}$ and dementia [46]. Studies demonstrated that obesity (body-mass index $\geq 30 \mathrm{~kg} / \mathrm{m}^{2}$ ) was an additional contributor to excess risk of all types dementias including AD [47] .Fitzpatrick et al reported that obesity in midlife was a significant increased risk factor for dementia. On the other side, there was a significant 
association between obesity and a reduced dementia risk in older patients [41]. Evidence suggests that low body-mass index in the elderly appears to be associated with an increased risk of cognitive dysfunction and $\mathrm{AD}[49,50]$.

\section{Micro-and Macro Vascular Complications}

There is a recognized association between macro- and micro vascular disease and pathogenesis of dementia. Cerebral micro vascular disease like lacunar infarcts are frequently found in people of $\mathrm{AD}$ with diabetes. The mechanism of cerebrovascular disease in people with type 2 diabetes is linked with multiple metabolic and haemodynamic defects [51, 52]. Studies in patients with type 1 diabetes, advanced micro vascular disease was known to be associated with poorer cognitive performance [53-55]. However cross-sectional studies in patients with type 2 diabetes did not show a compatible association between mild micro vascular disease and cognition [56,57].

Diabetes is one of the established risk factors for atherosclerotic disease [58]. In patients with type 2 diabetes with an atherosclerotic disease was found to be associated with cognitive impairment $[44,59,60]$. Moreover, cognitive impairment was found in patients with stroke in diabetes or peripheral arterial disease. [43, 61].

Studies on cognitive function of patients with type 2 diabetes, a history of macro vascular disease and elevated HbAlc levels were the most consistent risk factors for cognitive dysfunction. Even without macro vascular disease; type 2 DM was still associated with cognitive decrements, showing that the vascular risk factors were merely affecting cognitive impairment $[59,62,63]$.

\section{Genetic Factors}

\section{ApoE}

ApoE- $\varepsilon 4$ is associated with an increased risk for cognitive impairment and AD.The Cardiovascular Health Study showed that subjects with any ApoE- $\varepsilon 4$ allele with DM have an increased risk of cognitive decline than those without the ApoE- 84 alle [64].

The studies provided evidence that type 2 diabetes with ApoE- $\varepsilon 4$ allele had a higher risk of cognitive decline or dementia $[65,66]$. Another factor, insulin-degrading enzyme is indicated to intervene the connection between type 2 diabetes and Alzheimer's disease [67]. Insulindegrading enzyme breakdowns insulin and amyloid- $\beta$, the main component of amyloid plaques deposited in the brain of patients with $\mathrm{AD}$. The risk of type 2 diabetes and $\mathrm{AD}$ was higher in the conditions with changes the insulindegrading enzyme $[68,69]$.

\section{Depression}

Depression is a recognized risk factor for cognitive impairment in patients with diabetes. Patients with type 2 diabetes have a higher rate of depression, compared to nondiabetic persons [70]. The proportion of depressive cases was $31 \%$ in the patients with type 2 diabetes and a major depressive disorder was comprised of a $11 \%$. [61]. The relationship of type 2 diabetes and depression is merely understood. It is postulated that depression is due to dysfunction of neurotransmitters resulting from metabolic changes of type 2 DM [71].Besides that, depression might result from cerebro vascular disease in the brain[72,73].Moreover, the relation between diabetes and depression may be bidirectional as type 2 diabetes may develop from depression [74].

\section{Others}

\section{Inflammation}

The inflammatory process is involved in the development of macro vascular disease, one of the risk factors for $\mathrm{AD}$ in patients with type 2 diabetes. Studies showed that there was an association between systemic inflammatory marker-reactive protein and increased risk of $\mathrm{AD}[75,76]$. As and evidence; inflammatory cytokine IL-6 is present in senile plaques in $\mathrm{AD}$ patients [77].

Insulin resistance, a main feature of type 2 diabetes is associated with elevated levels of the inflammatory markers like interleukin-6, C-reactive protein and Alpha-1 antichymotrypsin [77, 78]. Raised inflammatory markers in type 2 DM correlates with an increased risk of cognitive decline and or dementia [26].

\section{Treatment of Cognitive Impairment \& AD in Type 2 DM}

To date there is no effective and curative therapy for poor cognitive function in type $2 \mathrm{DM}$. However, there are studies revealed that modest cognitive decline in patients with type $2 \mathrm{DM}$ were partially reversible with improvement of glycemic control, but that concept is still uncertain [79].

\section{Glycemic Control on Cognitive Function}

Intensive diabetic therapy vs conventional diabetes therapy

The DCCT trial indicated that there was no evidence of differences in cognitive improvement between patients with type 1 diabetes on conventional treatment and those with intensive treatment [32].

The studies, (UKPDS 1999 and ADVANCE) were designed to compare the effect of intensive inpatient glycemic treatment with standard treatment on cognitive function in patients with type 2 diabetes. Both studies showed that the difference between these two groups was statistically insignificant [80,81]. This finding was supported by ACCORD MIND (Memory in Diabetes) 
study; a sub study of ACCORD, a randomized study to evaluate the effect of intensive glucose lowering on cognitive function in elderly type 2 diabetes. The results of this study suggested that there was no significant effect on cognitive function by intensive glycemic control [80-82].

\section{Role of Antidiabetic Agents in Alzheimer's Disease}

\subsection{Clinical Trials of Antidiabetic Agents in Alzheimer's Patients}

There is some evidence that antidiabetic agents have potential benefits in treating Alzheimer's disease (AD). Studies on the effect of antidiabetic agents such as intranasal insulin, rosiglitazone (RSG), pioglitazone (PGZ), and metformin in non-diabetic AD patients have shown a possible pathophysiological association between diabetes and $\mathrm{AD}$.

Following trials have been done to evaluate the potential benefits of antidiabetic drugs in Alzheimer's patients.

\subsection{Peroxisome Proliferator-Activated Receptor- $\Gamma$ (Pparg) Agonists}

The studies concluded that glitazone activates PPAR that decreases plasma glucose by (1) directly intensify insulinmediated glucose up-take in skeletal muscle, (2) directly suppressing hepatic glucose production and (3) indirectly by transcriptional up regulation of adiponectin expression in adipose tissue. In addition, it acts on PPAR-gamma receptors in the brain, anti inflammatory, neuroprotective and neurotropic effect of rosiglitazone could be a potential mechanism of action in treating AD. Peroxisome proliferator-activated receptor- $\gamma$ is a key neuromodulator found in increased amounts in the brain of $\mathrm{AD}$ patients . Peroxisome proliferator-activated receptor- $\gamma$ plays various processes supposed to be considered the pathogenesis of both diabetes and AD. Thiazolidinediones (in particular, rosiglitazone and pioglitazone) diminish cerebral inflammation through inhibition of IL-6 and tumor necrosis factor. Such actions create a theory to regulate the rapid growth of $\beta$-amyloid peptide and enhance cognitive function in $\mathrm{AD}$ patients [83, 84].

There were studies which demonstrated the potential benefits of PPAR $\gamma$ agonists in patients with type $2 \mathrm{DM}$ and mild cognitive impairment and/or mild to moderate AD. [85]

The results of Watson et al. [86] showed a direct relationship between insulin levels and cognitive improvement in the rosiglitazone group compared with a placebo group. Another, two recent pilot studies [87, 88] are consistent with the findings of Watson et al .

In summary, based on the studies reviewed, thiazolidinediones might aid an adjuvant therapeutic benefit in patients of $\mathrm{AD}$ with type $2 \mathrm{DM}$.

\subsection{Insulin Therapy}

Massimiliano et al 2009 studied effects of insulin therapy on cognitive impairment in patients with Alzheimer disease and type 2 diabetes. A total of 104 patients with type 2 DM and $\mathrm{AD}$ were divided into 2 groups; group $\mathrm{A}$, patients assigned oral antidiabetic drugs and group B, assigned insulin combined with other oral antidiabetic agents. Cognitive function was assessed by the Mini Mental State Examination (MMSE) and the Clinician's Global Impression (CGI). The study indicated that MMSE scores showed a significant low in $56.5 \%$ patients of group A and in $23.2 \%$ patients of group B, compared to baseline MMSE scores. [89, 90]

This study suggested that insulin therapy could have benefited in decrease cognitive decline in patients with AD.

\subsection{Intranasal Insulin}

Intranasal insulin enhances brain insulin signaling in patients with $\mathrm{AD}$ with no effect on peripheral insulin levels. Intranasal insulin has been shown to increase CSF insulin which causes e memory improvement within a very short period of time in older adults with MCI and AD. Animal models confirm intranasal insulin makes a rapid appearance in areas important to memory, including the hippocampus. Insulin follows extracellular pathways and directly to the brain within 15 minutes .There was no risk of hypoglycemia as large amount of insulin bypassed peripherally .Two randomized placebo-controlled trials supported the beneficial effects of intranasal insulin on memory in subjects with dementia. [90,91].

\subsection{Metformin}

Metformin is a biguanide that enhance insulin-sensitivity, increase glucose uptake, decrease hepatic glucose synthesis, activate AMP activated protein kinase (AMPK, an enzyme involved in glucose and fatty acid metabolism), and cause mitochondria inhibition.

It probably acts independently of the PPAR pathways, has a similar effect on APP/A $\beta$ metabolism. The cohort study of Chih et al showed that sulfonylureas and metformin decreases the risk of dementia in patients with diabetes by $35 \%$ over 8 years [92]. Further studies of mechanisms of metformin action could contribute to its wider use for the prevention of type $2 \mathrm{DM}$, cancer, and Alzheimer's disease. This finding has been supported by some studies to explore the potential benefits of metformin therapy on cognitive function in patients with type $2 \mathrm{DM}$ [93].

\subsection{Glucagon-Like Peptide-1 Analogue}

Glucagon-like peptide-1 (GLP-1), secreted from the gastrointestinal tract lower blood glucose level by increasing insulin secretion by the pancreatic islet $\beta$ cell proliferation. It also has neurotrophic properties through GLP-1 receptors and can reduce the amyloid- $\beta$ peptide (A $\beta)$ 
in the hippocampus which is a pathological marker of $\mathrm{AD}$. GLP-1 may also be important for the production of new nerve cells in the mouse brain [94].

This potential therapeutic effect of GLP-1 analogue in $\mathrm{AD}$ was supported by one animal (Alzheimer's mouse) study which demonstrated the neurotrophic effect of GLP-1 analogue by reducing $A \beta$ levels in the mice brain [95]

\section{Conclusion}

This review article provides the association of diabetes in the pathogenesis of $\mathrm{AD}$. It highlights that management of vascular risk factors may be beneficial for preventing cognitive decline and dementia including Alzheimer's disease in persons with type $2 \mathrm{DM}$. There is no definite consensus about the value of any type of diabetic treatment to prevent cognitive impairment in people with Type 2 DM. However recent data suggest that antidiabetic agents such as intranasal insulin, rosiglitazone (RSG), pioglitazone (PGZ), and metformin could have potential benefit to promote cognitive impairment in patients with $\mathrm{AD}$. This knowledge may assist to motivate researchers to make greater efforts on potential new pharmacotherapy for $\mathrm{AD}$ patients.

\section{Data Sources}

All the relevant articles from Medline, PubMed and Medscape were searched using the key terms Alzheimer's disease, dementia, antidiabetic agents and type $2 \mathrm{DM}$.

\section{Acknowledgments}

The special thanks go to my helpful supervisor, Prof. Dato Dr. Khalid Bin Abdul Kadir for proof reading this report. The authors of this report would like to extend our sincere acknowledgement to all the Library staffs from Clinical School Johor Bahru especially to Zubaidah Binti Abd Rahman, Farah Raihana Binti Mohd Yasin, Mohd Azrul Azwan Ngahat, Norhidayah Binti Jamiaan for assistance with literature resources.

\section{References}

[1] Ferri CP, Prince M, Brayne C, et al. Alzheimer's Disease International. Global prevalence of dementia: a Delphi consensus study. Lancet. 2005;366:2112-7.

[2] Alzheimer's Association. 2010 Alzheimer's disease facts and figures. Alzheimers Dement 2010; 6: 158-94.

[3] E Duron and Olivier Hanon. Vascular risk factors, cognitve decline, and dementia. Vasc Health Risk Manag. 2008 April; 4 (2): $363-381$.

[4] Allen KV, Frier BM, Strachan MW. The relationship between type 2 diabetes and cognitive dysfunction: longitudinal studies and their methodological limitations. Eur J Pharmacol. 2004;490:169-75.
[5] Curb JD, Rodriguez BL, Abbott RD, et al. Longitudinal association of vascular and Alzheimer's dementias, diabetes, and glucose tolerance. Neurology. 1999;52:971-5.

[6] Peila R, Rodriguez BL, Launer LJ., Honolulu-Asia Aging Study Type 2 diabetes, APOE gene, and the risk for dementia and related pathologies: The Honolulu-Asia Aging Study. Diabetes. 2002;51:1256-62.

[7] Yamada M, Kasagi F, Sasaki H, et al. Association between dementia and midlife risk factors: the Radiation Effects Research Foundation Adult Health Study. J Am Geriatr Soc. $2003 ; 51: 410-4$.

[8] Schnaider Beeri M, Goldbourt U, Silverman JM, et al. Diabetes mellitus in midlife and the risk of dementia three decades later. Neurology. 2004;63:1902-7.

[9] Biessels GJ, Staekenborg S, Brunner E, et al. Risk of dementia in diabetes mellitus: a systematic review. Lancet Neurol. 2006;5:64-74.

[10] Yael D. Reijmer, Esther van den Berg, Carla Ruis. Cognitive dysfunction in patients with type 2 diabetes. Diabetes Metab Res Rev 2010; 26: 507-519.

[11] Luchsinger JA, Tang MX, Stern Y, Shea S, Mayeux R. Diabetes mellitus and risk of Alzheimer's disease and dementia with stroke in a multiethnic cohort. $\mathrm{Am} \mathrm{J}$ Epidemiol 2001; 154:635-641.

[12] Solfrizzi V, Panza F, Colacicco AM, et al. Vascular risk factors, incidence of $\mathrm{MCI}$, and rates of progression to dementia. Neurology 2004; 63: 1882-1891.

[13] T. Cukierman, H. C. Gerstein and J. D. Williamson.Cognitive decline and dementia in diabetessystematic overview of prospective observational studies.2005, Volume 48, Number 12, Pages 2460-2469.

[14] Yos. itake T, Kiyohara Y, Kato I, et al. Incidence and risk factors of vascular dementia and Alzheimer's. Disease in a defined elderly Japanese population: the Hisayama Study. Neurology1995; 45: 1161-1168

[15] Ott A, Stolk RP, van Harskamp F, Pols HA,et al. Diabetes mellitus and the risk of dementia: The Rotterdam Study. Neurology 1999; 53: 1937-1942.

[16] Peila R, Rodriguez BL, Launer LJ. Type 2 diabetes, APOE gene, and the risk for dementia and related pathologies: The Honolulu-Asia Aging Study. Diabetes 2002; 51: 1256-1262.

[17] XuWL, Qiu CX, Wahlin A, Winblad B, Fratiglioni L. Diabetes mellitus and risk of dementia in the Kungsholmen project: a 6-year follow-up study. Neurology 2004; 63: 1181-1186. XuWL,

[18] Thomas J, Steven T, et al. Clinical manifestations and diagnosis of Alzheimer disease: J Neurology and psychiatry; September 2010.

[19] Kua EH. The prevalence of dementia in elderly Chinese. Acta Psychiatr Scand 1991: 83: 350-352.

[20] E. Rönnemaa, B. Zethelius, J. Sundelöf, et al.Glucose metabolism aZetheliussk of Alzheimer's disease and dementia: a population-based 12 year follow-up study in 71year-old men: 2009, Volume 52. Number 8, Pages 15

[21] Neumann KF, Rojo L, Navarrete LP, et al. Insulin resistance and Alzheimer's disease: molecular links and clinical 
implications. Curr Alzheimer Res 2008 (5): 438-447.

[22] De Felice FG, Vieira MN, Bomfim TR et al .Protection of synapses against Alzheimer's-linked toxins: Insulin signalling prevents the pathogenic binding of A (beta) oligomers. Proc Natl Acad Sci U S A 10:1971-1976.

[23] Araki A. Dementia and insulin resistance in patients with diabetes mellitus. Nihon Rinsho.2010 Mar; 68 (3): 569-74.

[24] Hsueh, W. Genetic discoveries as the basis of personalized therapy: rosiglitazone treatment of Alzheimer's disease : The Pharmacogenomics Journal6. 4 (Jul 2006): 222-4.

[25] Pasquier F , Boulogne A , Leys D , Fontaine P. Diabetes mellitus and dementia.Diabetes Metab 2006;32:403.

[26] Mark W. J. Strachan, Rebecca M. Reynolds, Brian M. Frier, The relationship between type 2 diabetes and dementia. $\mathrm{Br}$ Med Bull (2008) 88 (1): 131-146.

[27] Strachan MWJ.. Insulin and cognitive function. Lancet 2003;362. 1253 (letter).

[28] Kuusisto J, Koivisto K, Mykkanen L, et al. Essential hypertension and cognitive function. The role of hyperinsulinemia. Hypertension. 1993;22:771-779.

[29] Almijn S,Feskens EJM, Launer LJ, et al.Glucose intolerance, hyperinsulinaemia and cognitive function in a general population of elderly men. Diabetologia 1995;38:1096-1102.

[30] Stolk RP, Breteler MMB, Ott A, et al. Insulin and cognitive function in an elderly population. The Rotterdam study. Diabetes Care 1997;20:792-795.

[31] Gold PE. Role of glucose in regulating the brain and cognition. Am J Clin Nutr 1995;61:987S-95S.

[32] The Diabetes Control and Complications Trial/Epidemiology of Diabetes interventions and Complications (DCCT/EDIC) Study Research Group. Intensive Diabetes Treatment and Cardiovascular Disease in Patients with Type 1 Diabetes. New England Journal of Medicine; 2005 vol. 353 no. 25

[33] Kumari M, Brunner E, Fuhrer R. Minireview: mechanisms by which the metabolic syndrome and diabetes impair memory. J Gerontol A Biol Sci Med Sci. 2000;5: B228-32.

[34] Xu WL, Qiu CX, Wahlin A, Winblad B, Fratiglioni L.Diabetes mellitus and risk of dementia in the Kungsholmen project: a 6-year follow-up study. Neurology. 2004 Oct 12;63 (7): 1181-6.

[35] Deary IJ. Symptoms of hyperglycemia and effects on mental performance and emotions. In Hypoglycaemia in Clinical Diabetes, (2nd edn), Frier BM, Fisher M (Eds). John Wiley $\&$ Sons: Chichester, 2007; 25.

[36] Warren RE, Frier BM. Hypoglycemia and cognitive function. Diabetes Obes Metab 2005; 7: 493-503.

[37] Bruce DG, Davis WA, Casey GP, et al. Severe hypoglycemia and cognitive impairment in older patients with diabetes: The Fremantle Diabetes Study. Diabetologia 2009; 52: 1808-1815.

[38] Snowdon DA, Greiner LH,et al. Brain infarction and the clinical expression of Alzheimer's disease. The Nun Study. $J$ Am Med Assoc 1997;277:813-7.
[39] Kloppenborg RP, van den Berg E, Kappelle LJ, Biessels GJ. Diabetes and other vascular risk factors for dementia: which factor matters most? A systematic review. Eur J Pharmacol 2008; 585: 97-108.

[40] Gustafson D. A life course of adiposity and dementia. EurJ Pharmacol 2008; 585: 163-175.

[41] Skoog I, Lernfelt B, Landahl S, et al. 15-year longitudinal study of blood pressure and dementia. Lancet 1996; 347: 1141-1145.

[42] Bruehl H, Wolf OT, Sweat V, Tirsi A, Richardson S, Convit A. Modifiers of cognitive function and brain structure in middle aged and elderly individuals with type 2 diabetes mellitus. Brain Res 2009; 1280: 186-194.

[43] Bruce DG, Davis WA, Casey GP, et al. Predictors of cognitive impairment and dementia in older people with diabetes. Diabetologia 2008; 51: 241-248.

[44] Manschot SM, Biessels GJ, de Valk HW, et al. Metabolic and vascular determinants of impaired cognitive performance and abnormalities on brain magnetic resonance imaging in patients with type 2 diabetes. Diabetologia 2007; 50: $2388-2397$.

[45] van den Berg E, Dekker JM, Nijpels G, et al. Blood pressure levels in pre-diabetic stages are associated with worse cognitive functioning in patients with type 2 diabetes. Diabetes MetabRes Rev 2009; 25: 657-664.

[46] Goodpaster BH, Krishnaswami S, Harris TB, Katsiaras A,Kritchevsky SB, Simonsick EM,et al.Obesity, regional body fat distribution, and the metabolic syndrome in older men and women. Arch Intern Med 2005; 165: 777-83.

[47] Beydoun MA, Lhotsky A,Wang Y, Dal Forno G, An Y,Metter EJ, Ferrucci L, et al. AB. An association of adiposity status and changes in early mid-adulthood with incidence of Alzheimer's disease. Am J Epidemiol 2008; 168: 1179-89.

[48] Fitzpatrick AL, Kuller LH, Lopez OL, et al. Midlife and late-life obesity and the risk of dementia: cardiovascular health study. Arch Neurol 2009; 66: 336-42.

[49] Dahl AK, Lopponen M, Isoaho R, Berg S, Kivela SL. Overweight and obesity in old age are not associated with greater dementia risk. J Am Geriatr Soc 2008; 56: 2261-66

[50] Knopman DS, Edland SD, Cha RH, Petersen RC, Rocca WA. Incident dementia in women is preceded by weight loss by at least a decade. Neurology 2007; 69: 739-46.

[51] Biessels GJ, Staekenborg S, Brunner E, Brayne C, Scheltens P. Risk of dementia in diabetes mellitus: a systematic review. Lancet Neurol 2006; 5: 64-74.

[52] Iehuis AM, van der Graaf Y, Visseren FL, et al . Diabetes increases atrophy and vascular lesions on brain MRI in patients with symptomatic arterial disease. Stroke 2008;39:1600-1603.

[53] Ferguson SC, Blane A, Perros P, et al. Cognitive ability and brain structure in type 1 diabetes: relation to microangiopathy and preceding severe hypoglycemia. Diabetes 2003; 52:149-156.

[54] Ryan CM, Geckle MO, Orchard TJ. Cognitive efficiency declines over time in adults with Type 1 diabetes: effects of 
micro- and macrovascular complications. Diabetologia 2003;46: 940-948.

[55] Wessels AM, Rombouts SA, Remijnse PL, et al. Cognitive performance in type 1 diabetes patients is associated with the cerebral white matter volume. Diabetologia 2007; 50: $1763-1769$.

[56] De Luis DA, Fernandez N, Arranz M, Aller R, Izaola O. Total homocysteine and cognitive deterioration in people with type 2 diabetes. Diabetes Res Clin Pract 2002; 55: 185-190.

[57] Beckman JA, Creager MA, Libby P. Diabetes and atherosclerosis: epidemiology, pathophysiology, and management. JAMA2002; 287: 2570-2581.

[58] van den Berg E, de Craen AJ, Biessels GJ, Gussekloo J,Westendorp RG. The impact of diabetes mellitus on cognitive decline in the oldest of the old: a prospective population-based study. Diabetologia 2006; 49: 2015-2023.

[59] Umegaki H, Iimuro S, Kaneko T, et al. Factors associated with lower Mini Mental State Examination scores in elderly Japanese diabetes mellitus patients. Neurobiol Aging 2008; 29:1022-1026.

[60] Brands AMA, van den Berg E, Manschot SM, et al. A detailed profile of cognitive dysfunction and its relation to psychological distress in patients with type 2 diabetes mellitus. J Int Neuropsychol Soc 2007; 13: 288-297.

[61] van den Berg E, Dekker JM, Nijpels G, et al. Cognitive functioning in elderly persons with type 2 diabetes and metabolic syndrome: the Hoorn study. Dement Geriatr CognDisord 2008; 26: 261-269.

[62] Kalmijn S, Feskens EJM, Launer LJ, Kromhout D. Cerebrovascular disease, the apolipoprotein $\varepsilon 4$ allele, and cognitive decline in a community-based study of elderly men. Stroke 1996;27:2230-5.

[63] HaanMN, Shemanski L, JagustWJ,et al. The role of APOE epsilon4 in modulating the effects of other risk factors for cognitive decline in elderly persons. JAMA 1999;282: 40-46.

[64] Blair CK, Folsom AR, Knopman DS,et al. APOE genotype and cognitive decline in a middle-aged cohort. Neurology 2005; 64: 268-276.

[65] 65Qiu WQ, Folstein MF. Insulin, insulin-degrading enzyme and amyloid-beta peptide in Alzheimer's disease: review and hypothesis. Neurobiol Aging 2006; 27: 190-198.

[66] Edland SD, Wavrant-De-Vriese F, Compton D, et al. Insulin degrading enzyme (IDE) genetic variants and risk of Alzheimer's disease: evidence of effect modification by apolipoprotein E (APOE). Neurosci Lett 2003; 345: 21-24.

[67] Edland SD. Insulin-degrading enzyme, apolipoprotein E, and Alzheimer's disease. J Mol Neurosci 2004; 23: 213-217.

[68] Anderson RJ, Freedland KE, Clouse RE, Lustman PJ. The prevalence of comorbid depression in adults with diabetes: a meta-analysis. Diabetes Care 2001; 24: 1069-1078.

[69] Krabbe KS, Nielsen AR, Krogh-Madsen R, et al. Brainderived neurotrophic factor (BDNF) and type 2 diabetes. Diabetologia2007; 50: 431-438.

[70] Baldwin RC, O’Brien J. Vascular basis of late-onset depressive disorder. Br J Psychiatry 2002; 180: 157-160.
[71] Bruce DG, Casey G, Davis WA, et al. Vascular depression in older people with diabetes. Diabetologia 2006; 49: 2828 2836

[72] Knol MJ, Twisk JWR, Beekman ATF, et al. Depression as a risk factor for the onset of type 2 diabetes mellitus. A metaanalysis. Diabetologia 2006; 49:837-845

[73] Schmidt R, Schmidt H, Curb JD, Masaki K, et al. Early inflammation and dementia: a 25-year follow-up of the Honolulu-Asia Aging Study. Ann Neurol 2002; 52: 168-74.

[74] Engelhart MJ, Geerlings MI,Meijer J, Kiliaan A,et al. Inflammatory proteins in plasma and the risk of dementia: the Rotterdam study. Arch Neurol 2004; 61: 668-72.

[75] Hak AE, Pols HA, Stehouwer CD, Meijer J, et al. Markers of inflammation and cellular adhesion molecules in relation to insulin resistance in nondiabetic elderly: the Rotterdam study. J Clin Endocrinol Metab 2001; 86: 4398-405.

[76] Hotamisligil GS. Inflammatory pathways and insulin action. Int J Obes Relat Metab Disord 2003; 27 (Suppl. 3): S53-5.

[77] Columbia University, Institute for the Study of Aging, National Institute on Aging. Metformin in amnestic mild cognitive impairment (MCI). Available at top: //clinical trials. Gov/ct2/show/NCT00620191 (last accessed 19 August 2010).

[78] Killick R, Scales G, Leroy K, Causevic M, et al. Deletion of Irs 2 reduces amyloid deposition and rescues behavioral deficits in APP transgenic mice. Biochem Biophys Res Comm 2009; 386: 257-62.

[79] Paromita King, Ian Peacock, Richard Donnelly.The UK Prospective Diabetes Study (UKPDS): clinical and therapeutic implications for type 2 diabetes. $\mathrm{Br} J$ Clin Pharmacol. 1999 November; 48 (5): 643-648.

[80] UK Prospective Diabetes Study Group.Quality of life in type 2 diabetic patient patients is affected by complications but ot by intensive policies to improve blood glucose or blood pressure control.Diabetes care 1999;22(7):1125-36.

[81] A. P. Kengne, A. Patel, S. Colagiuri, S. Heller and P. Hamet, et al.The Framingham and UK Prospective Diabetes Study (UKPDS) risk equations do not reliably estimate the probability of cardiovascular event. in a large ethnically diverse sample of patients with diabetes: the Action in Diabetes and Vascular Disease: Preterax and Diamicron-MR Controlled Evaluation (ADVANCE) Study.2010, Volume 53, Number 5, Pages 821-831.

[82] Williamson JD, Miller ME, Bryan RN, Lazar RM, Coker LH, Johnson J, Cukierman T.ect. The Action to Control Cardiovascular Risk in Diabetes Memory in Diabetes Study (ACCORD-MIND): rationale, design, and methods. ACCORD Study Group:Am J Cardiol. 2007 Jun 18;99 (12A): $112 \mathrm{i}-122 \mathrm{i}$.

[83] Takashi Sakurai, MD, PhD. Targets of the Peroxisome Proliferator-Activated Receptor _ Agonist Trials for the Prevention of Alzheimer Disease: $\bar{A}$ rch neurol/VOL 68 (NO. 4), APR 2011; Pg 542

[84] Luis Escribano, Ana-María Simón, Alberto PérezMediavilla, Pablo Salazar-Colocho, Joaquín Del Río,Diana Frechilla. Rosiglitazone reverses memory decline and hippocampal glucocorticoid receptor down-regulation in an Alzheimer's disease mouse model: Biochemical and 
Biophysical Research Communications 379 (2009) 406-410

[85] C. Harrington, S. Sawchak, C. Chiang, J. Davies, C. Donovan, A.M. Saunders, et al. Rosiglitazone Does Not Improve Cognition or Global Function when Used as Adjunctive Therapy to AChE Inhibitors in Mild-toModerate Alzheimer's Disease: Two Phase 3 Studies: Current Alzheimer Research, 2011, 8, 592-606

[86] Watson GS, Cholerton BA, Reger MA, Baker LD, Plymate $\mathrm{SR}$,Asthana S,et al. Preserved cognition in patients with early Alzheimer disease and amnestic mild cognitive impairment during treatment with rosiglitazone: a preliminary study. Am J Geriatr Psychiatry 2005; 13:950-8

[87] Sato T, Hanyu H, Hirao K, Kanetaka H, Sakurai H, Iwamoto T. Efficacy of PPAR-gamma agonist pioglitazone in mild Alzheimer disease. Neurobiol Aging in press

[88] Hanyu H, Sato T, Kiuchi A, Sakurai H, Iwamoto T. Pioglitazone improved cognition in a pilot study in patients with Alzheimer's disease and mild cognitive impairment with diabetes mellitus. J Am Geriatr Soc 2009;57: 177-9

[89] Massimiliano Plastino , Antonietta Fava , Domenico Pirritano , Piero Cotronei, Natalina Sacco, Teresa Sperlì ,et al.Effects of insulinic therapy on cognitive impairment in patients with Alzheimer disease and Diabetes Mellitus type2; Journal of the Neurological Sciences 288 (2010) 112-116

[90] Suzanne Craft, PhD; Laura D. Baker, PhD; Thomas J. Montine, MD, PhD; Satoshi Minoshima, MD,et al.Intranasal Insulin Therapy for Alzheimer Disease and Amnestic Mild Cognitive Impairment.: A Pilot Clinical Trial ;Author Affiliations: Geriatric Research, Education, and Clinical Center (Drs Craft, Baker, Watson, Claxton,
Callaghan, and Plymate and $\mathrm{Mr}$ Arbuckle) and Mental Illness Research, Education, and Clinical Center (Drs Leverenz and Gerton), Veterans Affairs Puget Sound Health Care System, and Departments of Psychiatry and Behavioral Sciences (Drs Craft, Baker, Watson, Claxton, and Leverenz), Pathology (Dr Montine), Radiology (Drs Minoshima and Cross), Medicine (Drs Tsai, Plymate, and Green), and Neurology (Drs Leverenz and Gerton), University of Washington School of Medicine, Seattle, Arch Neurol. 2012;69(1):29-38

[91] Helgi B Schiöth, William H Frey .Insulin to Treat Alzheimer's Disease: Expert Rev Clin Pharmacol. 2012;5(1):17-20. (C) 2012 Expert Reviews Ltd.

[92] Chih-Cheng Hsua, Mark L. Wahlqvista, Meei-Shyuan Leec and Hsin-Ni Tsaia. Incidence of Dementia is Increased in Type 2 Diabetes and Reduced by the Use of Sulfonylureas and Metformin. Journal of Alzheimer's Disease 24 (2011) 485-493.

[93] Grzybowska M, Bober J, Olszewska M. Metformin mechanisms of action and use for the treatment of type 2 diabetes mellitus]. Postepy Hig Med Dosw (Online). 2011 May 6;65:277-85.

[94] Luchsinger JA. Type 2 diabetes, related conditions, in relation and dementia: an opportunity for prevention? $J$ Alzheimers Dis. 2010;20(3):723-36. Review.

[95] Stephen F.J, McGovern, Kerry Hunter, Christian Hölscher.Effects of the glucagon-like polypeptide-1 analogue (Val8)GLP-1 on learning, progenitor cell proliferation and neurogenesis in the $\mathrm{C} 57 \mathrm{~B} / 16$ mouse brain.BrainResearch,2012;1473:204 